\title{
Direito Tributário Sanitário - Das Taxas de Fiscalização Sanitária e seus Problemas Atuais - UMa Forma de IdentificaÇão dos Erros Na Busca de Soluções
}

TRIBUTARY HEALTH SURVEILLANCE LAW - OF THE HEALTH

SURVEILLANCE ENFORCEMENT FEE AND ITS CURRENT

PROBLEMS - A WAY TO IDENTIFY MISTAKES

IN SEARCH FOR SOLUTIONS

Alexandre Nemer Elias ${ }^{(*)}$

\section{RESUMO}

O Sistema Nacional Tributário Sanitário é totalmente novo. Criado recentemente em 26 de janeiro de 1999 pela Lei n. 9.782, é pouco abordado pelos juristas e cientistas do direito. Porém, muito ao contrário do que se possa imaginar a respeito de artigos e trabalhos que abordam as peculiaridades do Sistema, ele está longe de se constituir num modelo de respeito à Constituição da República e ao Código Tributário Nacional. Portanto, nos impõe ressaltar aos cientistas juridicos os graves problemas evidenciados neste Sistema para que sejam discutidos na finalidade de buscar o aperfeiçoamento legal, afastando as ilegalidades e inconstitucionalidades, em caráter de urgência, já que prejudica tanto o setor privado quanto o setor público regulado.

\section{Descritores}

Direito tributário sanitário; Taxa de fiscalização sanitária federal; Sistema tributário sanitário; Poder regulatório; Legislação sanitária.

(") Advogado sanitarista e Especialista em Direito Processual Civil pela PUC - Campinas e Membro da Comissão de Defesa do Consumidor da OAB/SP - Campinas (SP). E-mail: nemer@ndadrogados.com.br. Recebido: 18.2.04, Aprovado: 9.5.04. 


\section{ABSTRACT}

The National Health Surveillance Fee System is totally new. Created recently, on January 26,1999 , through Law 9.782 , it is seldom approached by the jurists and law scientists. However, contrary to what one may assume regarding the articles and papers on the System's particularities, it is far from constituting itself into a model in respect to the National Constitution and the National Tributary Code. Therefore, it is our duty to point out to law scientists the grave problems found within the System so they can be discussed aiming legal improvement, removing the illegalities and unconstitutionalities, in character of urgency, since they damage both the private and regulated public sectors.

\section{Key words}

Tributary health surveillance law; Federal health surveillance enforcement fee; Tributary health surveillance system; Regulatory power; Health surveillance legislation.

\section{INTRODUÇÃO}

O Direito Tributário Sanitário(1) compõe-se de regras juridicas de natureza tributária criada especificamente com a finalidade de fomento ao sistema de fiscalização sanitário federal.

Apesar de ter o Direito Tributário as regras e conceitos especificos de seus institutos, pela peculiaridade do assunto, far-se-á necessária a adequação destes conceitos já consolidados ou firmados na doutrina tributária, dentro da ciência do que entendemos por Direito Sanitário(2).

(1) A professora Sueli Gandolfi Dallari já advertia, desde 1988, em seu artigo Uma nova disciplina: o direito sanitário. Revista de Saúde Pública, v. 22, n. 4, p. 327-334, agosto de 1988, que conclui-se, em um exame superficial, que o ensino do direito sanitário deve, portanto, incluir áreas como: Introdução à Filosofia e Sociologia do Direito Sanitário; Organização Juridica da Administração Sanitária; Direito Penal Sanitário; Direito dos Serviços de Saúde; Direito do Planejamento Sanitário; Direito Previdenciário Sanitário; Direito Internacional Sanitário; Ética Sanitária; Polícia Sanitária; e Direito Sanitário Comparado. Por isso, é importante sabermos separar as matérias deste ramo do direito no intuito de aprofundarmos nas peculiaridades existentes nesta.

(2) Novamente citamos a eminente professora Sueli Gandolfi Dallari que, juntamente com Rosemary Barber-Madden, Marilia de Castro Torres-Fernandes, Nur Shuqaira Mahmud Said Abdel Qader Shuqair e Helena Akemi Watanabe, estudaram a matéria da advocacia em saúde, concluindo, em encontro ao que entendemos, que as especificidades, as lacunas, as normas que regem cada Poder deverăo ser meticulosamente estudadas para a elaboração das estratégias de advocacia em saúde (Advocacia em saúde no Brasil contemporâneo. Revista de Saúde Pública, São Paulo, v. 30, n. 6, p. 592-601, dez. 1996). 
Como já dito, as taxas são, atualmente, uma das fontes de custeio do Sistema de Vigilância Sanitária Nacional. Para a ANVISA, a taxa faz parte, consoante o que dispõe o art. 22, I, da Lei n. 9.782, de 26 de janeiro de 1999 (Lei da ANVISA), do seu patrimônio. A grande problemática a que submetemos este estudo é na verificação da legalidade e da constitucionalidade no Sistema Tributário Sanitário federal, tendo em vista a criação e as modificações introduzidas na lei, fatores estes que rebatem a nós operadores desta especialidade do direito e que pouco tem sido abordado face à grande especificidade do ramo $^{(3)}$.

\section{DAS FONTES DO DIREITO TRIBUTÁRIO SANITÁRIO}

$\mathrm{Na}$ Constituição da República encontramos as principais normas sobre o tributo instituido pela Lei da ANVISA(4) devendo, através das normas constitucionais e legais gerais, pautarmos o que esta lei define como sendo a taxa de fiscalização sanitária( ${ }^{(5)}$.

A origem das taxas de fiscalização sanitária da ANVISA dá-se pela instituição feita através da Lei n. 9.782, de 26 de janeiro de 1999, art. 23, que, além de instituir e prever a taxa de fiscalização sanitária federal, especifica o fato gerador, o sujeito passivo tributário e as condições e as fontes e procedimentos para o seu pagamento. A forma utilizada pela Lei para a instituição da taxa de fiscalização sanitária é adequada ao Sistema Tributário vigente, pois, conforme explica Celso Ribeiro Bastos, não é qualquer lei que basta para satisfazer o principio no campo fiscal. Aduz, ele, que é preciso que a lei descreva o fato gerador da obrigação principal, determine a alíquota e a base de cálculo, os sujeitos ativos e passivos dos tributos, chamando para si todos os aspectos relevantes atinentes à criação, extinção e modificação da obrigação tributária, incluindo-se ai a definição de penalidades pelo seu não-cumprimento(6).

No entanto, após o grande e árduo trabalho do legislador, a lei foi alterada em relação aos fatos geradores e as aliquotas da taxa prevista

(3) Este tema remete-nos à clara colocação de Eduardo de Moraes Sabbag que nos impõe a não esquecermos de que são corriqueiras as violações ao Principio da Legalidade na seara das relaçōes juridico-tributárias, devendo o causidico que milita na vertente área atentar para a precisão da argüição, suscitando tal Principio, a fim de resguardar a segurança do sujeito passivo. (Elementos do direito - direito tributário. 5. ed., Sảo Paulo: Prima Cursos Preparatórios, 2004. p. 23).

(4) Lei n. 9.782, de 26 de janeiro de 1999.

(5) BASTOS, Celso Ribeiro. Curso de direito financeiro e direito tributário. 3. ed. Sảo Paulo: Saraiva, 1995. p. 162, explica que a Constituição da República molda através do Sistema Tributário Nacional, todo o resto do sistema tributário. Portanto, como o Direito Tributário Sanitário é dependente dos principios e do Sistema Tributário, devemos conceituar e identificar seus institutos e principios do sistema.

(6) Id. Ibid., p. 166. 
em seu Anexo II, através da Medida Provisória n. 2.190, de 23 de agosto de 2001 que, posteriormente, foi alterada pela Resolução RDC n. 236, de 26 de dezembro de 2001 e, depois, pela Resolução RDC n. 23, de 6 de fevereiro de 2003, hoje em vigor, consistindo, estas últimas duas, em normas administrativas inconstitucionais que não poderiam ampliar os fatos geradores, instituir isenções e, nem mesmo as aliquotas, constantes do Anexo II da Lei n. 9.782/99.

A sua natureza é de taxa de fiscalização sanitária da ANVISA, pois, esta será recolhida diretamente à Agência, por força do parágrafo único, do art. 22 da Lei da ANVISA. Os demais entes federados já possuem leis específicas de custeio prevendo a possibilidade da instituição das taxas estaduais e municipais de fiscalização sanitária. Ademais, ainda hoje subsiste esta duplicidade da cobrança das taxas previstas inclusive para o caso de drogarias e farmácias, até então não cobradas pela autarquia federal.

\section{DA NATUREZA JURIDICA E DO CONCEITO DAS TAXAS COBRADAS PELA ANVISA}

As taxas instituidas pela Lei de criação da ANVISA são verdadeiros tributos que correspondem ao exercicio do poder de policia fiscalizatório do mercado dos produtos relacionados à saúde.

Como bem assevera o professor Sacha Calmon Navarro Coelho(7), as taxas estão sujeitas aos principios fundamentais de contenção ao poder de tributar: legalidade, anterioridade, irretroatividade, não-confisco e capacidade contributiva ${ }^{(8)}$. Taxa, segundo Aliomar Baleeiro, é o tributo cobrado de alguém que se utiliza de serviço público especial e divisivel, de caráter administrativo ou jurisdicional, ou o tem à sua disposição, e ainda quando provoca em seu beneficio, ou por ato seu, despesa especial dos cofres públicos $^{(9)}$. Assim, foi adequada a instituição das referidas taxas, sem a qual, não se poderia fomentar a atividade fiscalizadora da autarquia - ANVISA.

(7) COELHO, Sacha Calmon Navarro. Comentários à Constituiçăo de 1988. 5. ed., Rio de Janeiro: Forense, 1993. p. 46.

(8) 0 eminente professor aduz que quanto a este principio - capacidade contributiva - a doutrina é dividida. Pare ele, existem leis que favorecem certas pessoas, fisicas ou juridicas, tendo em vista outros principios. Como o do interesse público se faz presente diante à necessidade de se ter produtos que promovam a saúde pública, este se sobressai à necessidade do Estado de impor uma oneração àqueles que não têm capacidade para suprir. Completando o pensamento ele fornece o exemplo do principio do acesso à justiça que não pode, em tese, ser limitado pela imposição das taxas judiciais.

(9) BALEEIRO, Aliomar. Direito tributário brasileiro. 9. ed., Rio de Janeiro: Forense, 1977, p. 292. 


\section{DO PRINCÍPIO DA LEGALIDADE E DA INSTITUIÇÃO DE FATOS GERADORES ATRAVÉS DAS RESOLUÇŌES DA ANVISA}

Parece-nos que essa matéria já está bem esgotada na doutrina e na jurisprudência tendo em vista a imposição ao princípio da legalidade e da reserva legal previstos na Constituição da República. No entanto, em relação às taxas de fiscalização sanitária federal, a exceção foge à regra. A ANVISA instituiu através das Resoluções RDC n. 23, de 6 de fevereiro de 2003 e a anterior Resolução RDC n. 236, de 26 de dezembro de 2001, aliquotas, valores, isenções e fatos geradores desrespeitando, frontalmente, os principios constitucionais da legalidade e da reserva legal.

Para analisarmos mais profundamente a questão, remetemos-nos ao art. 100 do Código Tributário Nacional que especifica como sendo normas complementares às Leis, os atos normativos expedidos pela autoridade administrativa.

Esses normativos administrativos são regras juridicas inferiores, hierarquicamente, às leis. Hugo de Brito Machado explica nestes termos que estes atos normativos administrativos não podem modificar as leis ${ }^{(10)}$. A lei é a única fonte formal originária da obrigação tributária(11). Rui Barbosa Nogueira, citando a Instrução Normativa n. 26, de 4 de junho de 1970, do Ministério da Fazenda, como paradigma a todos os atos normativos administrativos explica que estes (atos normativos administrativos) não podem criar direitos e obrigações, quando de outro lado a maior parte da fiscalização os aceita como se fosse legislação, sendo mais uma fonte de conflitos, pois os contribuintes prejudicados são constantemente obrigados a se defender perante a própria administração ou intentar ações judiciais ${ }^{(12)}$.

Portanto, é inconcebivel a utilização de Resoluções para a criação de obrigações tributárias aumentando os fatos geradores e o seu valor ${ }^{(13)}$.

\section{DA PROBLEMÁTICA NA INSTITUIÇÃO DO SUJEITO PASSIVO DAS TAXAS DE FISCALIZAÇÃO SANITÁRIA}

A Lei da ANVISA, em seu art. $23, \S 22^{\circ}$, especifica como sendo as pessoas físicas e juridicas que exercem atividades de fabricação, distri-

(10) MACHADO, Hugo de Brito. Curso de direito tributário, 4. ed., Rio de Janeiro: Forense, 1987, p. 62.

(11) Ruy Barbosa Nogueira. Op. cit., p. 55.

(12) Id. Ibid., p. 58.

(13) Na França, já é antigo o receio dos Tribunais em relação ao que se denomina "superpoderes" decorrente deste poder regulamentar das agências. Aqui também se faz necessário o estudo sobre o tema discricionariedade técnica, bem desenvolvido na doutrina administrativa Francesa e na Norte-Americana. Porém, tais assuntos são extensos e reclamam um estudo em apartado. Por isso, indicamos duas literaturas essenciais àqueles que desejam se aprofundar ao tema: GELLHORN, Ernest; LEVIN, Ronald M. Administrative law and process. Minesotta: West, 1997; e, GUÉDON, Marie-José. Les autorités administratives independentes. Paris: Librarie Générale de Droit et de Jurisprudence, 1991. 
buição e venda de produtos e a prestação de serviços mencionados no art. $8^{\circ}$. O interessante é que essa Lei não fez qualquer referencia à Lei $n$. $6.360 / 76$, que dispõe sobre as atividades das pessoas incidentes à fiscalização da vigilância sanitária.

$\mathrm{O}$ art. $2^{\circ}$ da Lei n. $6.360 / 76$ exemplifica, pormenorizadamente, as atividades incidentes à fiscalização sanitária quais sejam: extrair, produzir, fabricar, transformar, sintetizar, purificar, fracionar, embalar, reembalar, importar, exportar, armazenar ou expedir os produtos sujeitos ao controle sanitário. Portanto, existe uma falha na legislação quanto à imposição da taxa às pessoas que pratiquem tal atividade especifica sobre a qual incide o fato gerador. Tais atividades já estão expressas na legislação sanitária; porém, não correlatas à Lei da ANVISA.

\section{DO FATO GERADOR DA OBRIGAÇĀO TRIBUTÁRIA SANITÁRIA}

Os fatos geradores desta taxa estão no Anexo II da Lei n. 9.782/99. Ali encontraremos também o valor da taxa e a periodicidade de sua incidência sobre o sujeito passivo tributário. Esta é a redação da lei que, em seu art. 23, $\S 10$, especifica: constitui fato gerador da Taxa de Fiscalização de Vigilância Sanitária a prática dos atos de competência da Agência Nacional de Vigilância Sanitária constantes do Anexo II.

Fazendo uma interpretação sistemática encontramos no Código Tributário Nacional, em seu art. 77, que as taxas cobradas pela União, pelos Estados, pelo Distrito Federal ou pelos Municipios, no âmbito de suas respectivas atribuições, têm como fato gerador o exercicio regular do poder de polícia, ou a utilização, efetiva ou potencial, de serviço público especifico e divisivel, prestado ao contribuinte ou posto à sua disposição. Já no art. 114, ao conceituar o fato gerador da obrigação principal, a lei estabelece que é a situação definida em lei como necessária e suficiente à sua ocorrência.

Comentando estes dois artigos, o professor Arx Tourinho, verifica que, fora deste limite, não é possivel o surgimento da taxa ${ }^{(14)}$. Ainda assevera que a lei tributária que cria a taxa, tendo em vista o princípio da legalidade, deve especificar as situações enquadráveis nos lindes constitucionais.

O mesmo entendimento é compartilhado por Roque Antônio Carrazza que explica a hipótese de incidência tributária - sempre veiculada por meio de lei - deve conter uma exaustiva descrição dos pressupostos tributários, apta a permitir que todos eles sejam perfeitamente reconheci-

(14) TOURINHO, Arx. Comentários ao Codigo Tributário nacional. Rio de Janeiro: Forense, 1997. p. 140. 
dos, quando ocorrerem, no mundo fenomênico(15). Além disso, conforme o Código Tributário Nacional, a taxa deve ser decorrente de ato de poder de policia ou toda prestação de serviço público que possam ser especificas e divisiveis ${ }^{(16)}$.

Pasmem, mas no inicio, a Lei n. 9.782, de 26 de janeiro de 1999, possuia apenas 37 fatos geradores em seu Anexo II, que, ao contrário do entendimento unânime exposto, foi alterada pela Medida Provisória $n$. 2.190 , de 23 de agosto de 2001, segundo o qual, em seu Anexo, possui 158 fatos geradores. Depois disso, os fatos geradores foram ampliados pelas inconstitucionais resoluções administrativas (RDCs). A Resolução RDC n. 236, de 26 de dezembro de 2001, contém 432 fatos geradores em sua tabela nos Anexos I e II, reduzidos posteriormente pela, e em vigor, Resolução RDC n. 23, de 6 de fevereiro de 2003, para nada menos que 317 fatos geradores em sua tabela nos Anexos I e II.

Ora, apesar da clareza constitucional, reconhecemos que os superpoderes $^{(17)}$ conferidos à ANVISA têm transformado esta Agência numa verdadeira autarquia independente até mesmo do sistema juridico brasileiro.

\section{DAS ALIQQUOTAS E DOS VALORES DAS TAXAS}

Pautando-se pela legalidade e constitucionalidade, segundo a Lei $n$. $9.782 / 99$, são 32 fatos geradores instituidos que permitem a cobrança das taxas de fiscalização sanitária. Os valores constantes da tabela do Anexo II, ficam reduzidos, exceto nos casos dos itens 16.1, 16.2, 16.3, 16.4, em: $30 \%$ no caso de empresas médias tal qual definido pela Lei $n$. 9.531 , de 10 de dezembro de $1997 ; 60 \%$ no caso das pequenas empresas tal qual definido na Lei n. 9.317, de 5 de dezembro de 1996; e, $90 \%$ no caso das microempresas tal qual definido na Lei $n$. 9.317, de 5 de dezembro de 1996. Portanto, analisando os casos, para alguns fatos geradores a Medida Provisória e a Resolução RDC n. 23/2003 foram benéficas e, nos outros casos, foi maléfica aumentando o valor da taxa.

Em relação ao aumento temos que a majoração é inconstitucional. Já quanto à redução, se observarmos sob prisma da isenção tributária, apesar da Constituição da República não mencionar nada a respeito o Código Tributário Nacional determina em seu art. 177, que a isenção não pode ser extensiva às taxas salvo quando a lei dispuser ao contrário.

(15) CARRAZZA, Roque Antônio. Curso de direito constitucional tributário. 16. ed. São Paulo: Malheiros Ed., 2001. p. 371.

(16) COELHO, Sacha Calmon Navarro. Op. cit., p. 46.

(17) Os denominados "superpoderes" são a classificação que os juristas franceses deram para a atuação abusiva das Autorités Administratives Indépendantes francesas, poderes estes que sofreram repressão dos Tribunais (Administrativo e Judicial). A mesma experiência tiveram os norte-americanos que hoje possui tanto uma repressão efetiva destes "superpoderes" pelo poder Legislativo quanto pelo Judiciário aos atos administrativos regulatórios emitidos por sua Agency. 
Verificamos, porém, através de breve levantamento dos valores contidos no Anexo II da Lei da ANVISA, que algumas taxas ferem o principio do não-confisco tributário e o da capacidade contributiva já que institui às farmácias e drogarias uma taxa anual no valor de $R \$ 15.000,00$ (quinze mil reais).

Assim, concluimos que, atualmente, o sistema legal que instituiu e os atos normativos administrativos que alteraram a taxa de fiscalização sanitária está totalmente desvirtuado do contexto econômico empresarial do setor regulado.

\section{DA INCONSTITUCIONALIDADE DO ART. 25 DA LEI N. 9.782, DE 26 DE JANEIRO DE 1999}

Assim expressa o art. 25 da Lei n. 9.782/99: A Taxa de Fiscalização de Vigilância Sanitária será devida a partir de $1^{\circ}$ de janeiro de 1999.

Faz-se importante ressaltar que esta lei entrou em vigor na data de 27 de janeiro de 1999, ou seja, na data de sua publicação conforme o texto do art. 45 .

Assim determina a nossa Constituição da República, em seu art. 150: Sem prejuizo de outras garantias asseguradas ao contribuinte, é vedado à União, aos Estados, ao Distrito Federal e aos Municipios: (...) III cobrar tributos: a) em relação a fatos geradores ocorridos antes do início da vigência da lei que os houver instituido ou aumentado; b) no mesmo exercício financeiro em que haja sido publicada a lei que os instituiu ou aumentou.

O referido art. 25 , da Lei $n$. $9.782 / 99$, fere o principio constitucional da irretroatividade e o da anterioridade. O primeiro principio impede que uma lei possa alterar situações pretéritas sob pena de violar o direito adquirido, $o$ ato jurídico perfeito e os princípios da segurança jurídica e da legalidade. No entanto, temos algumas situações em que a lei tributária pode retroagir nas hipóteses do art. 106 do Código Tributário Nacional. Esses casos só se aplicarão quando a lei tributária for mais benéfica ao setor regulado.

Nesses termos, faz-se mister a lição do professor Aliomar Baleeiro que identifica estes casos quando o dispositivo dá interpretação autêntica a outro ou outros de lei anterior, exclui penalidade desta, e, ainda, quando assume a caracteristica de lex mition ${ }^{(18)}$.

Segundo o último princípio, nenhum tributo pode ser cobrado no mesmo exercicio financeiro em que foi instituido ou aumentado. Explica Celso Ribeiro Bastos que se um tributo (rectius: taxa) criado em junho

(18) BALEEIRO, Aliomar. Op. cit., p. 386 
deste ano, por exemplo, terá que aguardar o mês de janeiro do próximo ano para ser cobrado(19). $O$ artigo supracitado não se enquadra nas hipóteses descritas como exceção aos principios. Concluimos que o artigo é inconstitucional, devendo ser afastada do mundo jurídico.

\section{DAS NORMAS DE INSTITUIÇÃO DAS TAXAS E DA INCONSTITUCIONALIDADE DA ALTERAÇÃO DAS TAXAS PREVISTA NA MEDIDA PROVISÓRIA N. 2.190, DE 23 DE AGOSTO DE 2001 E PELA RESOLUÇÃO RDC N. 23, DE 6 DE FEVEREIRO DE 2003}

Sacha Calmon Navarro Coêlho é bem claro quando determina que é preciso lei, em sentido formal e material, para instituir taxas ${ }^{(20)}$. No entanto, essa forma que a constituinte deu ao Chefe do Poder Executivo de criar normas - já que a medida provisória não deve ser considerada como lei num conceito mais amplo - vem trazendo um grande problema para a sociedade segundo o qual já se teria resolvido diante o sistema da nova Constituição da República e pelo principio implícito contido nela da segurança jurídica.

Para nós, a medida provisória é uma verdadeira medida administrativa cautelar tendo seu caráter de urgência com base na primeira parte do art. 62 da Constituição da República, já que, se esperar o processo legislativo, corre-se o risco da lei não ter mais eficácias às situações fáticas atuais. No entanto, a instituição, majoração ou alteração das taxas não nos parece matéria que poderia constituir os requisitos definidos no art. 62 da Constituição da República.

Outra observação nossa é quanto à Emenda Constitucional de $\mathrm{n}$. 32 , de 2001 , especificamente no que dispõe seu art. $2^{\circ}$ determinando que as medidas provisórias editadas em data anterior à da publicação desta emenda continuam em vigor até que medida provisória ulterior as revogue explicitamente ou até deliberação definitiva do Congresso Nacional. Pelo disposto neste artigo permanecerão em vigor indefinidamente as MP's editadas em data anterior à publicação da EC n. 32/01, isto é, sem obediência nem ao prazo antigo de trinta dias, nem ao novo de sessenta, ficará valendo até que medida provisória ulterior as revogue explicitamente ou até deliberação definitiva do Congresso Nacional. Veja-se que nos dez dias que antecederam a Emenda, o Executivo editou nada mais, nada menos, que vinte e uma medidas provisórias (média de mais de duas por dia), todas elas dispondo sobre os mais diversos assuntos de interesse da União e, repita-se, nenhuma delas precisará ser reeditada, simplesmente continuarão a vigorar por prazo indeterminado. É translúcido e cla-

(19) BASTOS, Celso Ribeiro. Op. cit., p. 111.

(20) COELHO, Sacha Calmon Navarro. Op. cit., p. 46. 
rividente que as mesmas deveriam ficar limitadas no tempo, devendo o legislador ter fixado um termo final de validade das mesmas com ou sem apreciação pelo Congresso.

Além desta manobra para "legalizar" a alteração tributária, recebemos, a contragosto, a Resolução RDC n. 23/2003, ato normativo administrativo que alterou a legislação tributária para introduzir os anseios da Agência, ao sistema jurídico vigente.

Somos contra a utilização das Resoluções nos moldes atuais para a alteração da taxa. Contrariamos este sistema com fundamento nos principios constitucionais.

\section{DO PROCEDIMENTO DE RECOLHIMENTO DAS TAXAS}

De acordo com Roque Antônio Carrazza, em decorrência ao principio da legalidade, o prazo e as condições de recolhimento dos tributos só podem ser fixados ou alterados por meio de lei(21).

Este entendimento é compartilhado também por Geraldo Ataliba segundo o qual: fixar prazo para cumprimento de obrigação pecuniária não é matéria administrativa. É assunto que não comporta discrição. É matéria legal, porque diz respeito à quantificação da obrigação tributária do cidadão diante do Estado(22).

Na verdade, Geraldo Ataliba, como bem lembra Carrazza ${ }^{(23)}$, concebeu esse entendimento dentro da perspectiva do principio da reserva legal imposta para a fruição da garantia individual da segurança jurídica do poder de tributar. No entanto, a Lei da ANVISA é bem clara em determinar em seu art. $23, \S 4^{\circ}$, que: a taxa deverá ser recolhida nos prazos dispostos em regulamento próprio da Agência.

Ora, procedimentos administrativos devem respeitar o principio da legalidade, mormente quando falamos em procedimentos administrativos tributários.

Assim, tal parágrafo é inconstitucional além de todo sistema imposto pela ANVISA que, através da RDC, especificou o procedimento para o pagamento da taxa de fiscalização sanitária.

A inconstitucionalidade fica mais evidente quando se impõe, antes mesmo da efetivação do fato gerador, o pagamento da taxa em alguns casos previsto pela Resolução RDC n. 23, de 6 de fevereiro de 2003, que

(21) CARRAZZA, Roque Antônio. Op. cit., p. 46

(22) ATALIBA, Geraldo. Carga tributária e prazo de recolhimento de tributos. Revista de Direito Tributário, Sảo Paulo, n. 45, p. 27-29, jul./set.1988.

(23) Ibidem, idem. 
dispõe sobre normas básicas de procedimentos administrativos voltados para a melhoria do atendimento e da arrecadação no âmbito da Agência Nacional de Vigilância Sanitária - ANVISA.

Além desse normativo administrativo inconstitucional, podemos citar outro mais recente, a Resolução RDC n. 23, de 6 de fevereiro de 2003, que dispõe sobre normas básicas de procedimentos administrativos voltados para a melhoria do atendimento e da arrecadação no âmbito da Agência Nacional de Vigilância Sanitária - ANVISA.

$\mathrm{O}$ art. 35 desta Resolução determina que: Para efeitos de enquadramento nos valores, descontos e isenções da Taxa de Fiscalização de Vigilância Sanitária ficam instituidas as tabelas contidas nos Anexos I e II desta Resolução, nos termos dos fatos geradores constantes da Lei n. 9.782/ 99, com as alterações dadas pela Medida Provisória n. 2.190-34, de 23 de agosto de 2001. Portanto, a Administração alterou os valores e aliquotas constantes da Lei por meio da inconstitucional medida provisória e da ilegal Resolução supracitada.

Atualmente, para o denominado setor regulado requerer algo perante a Agência, este deve comprovar o recolhimento de alguma taxa ou a sua isenção, em casos excepcionais que é disciplinado pela RDC n. 23/2003. No entanto, através da unidade denominada UNIAP - Unidade de Atendimento ao Público, é feita a verificação documental das petições. Ela foi investida inconstitucionalmente na atividade de verificação procedimental que, se não cumprida, fica autorizada a proceder com o indeferimento do pedido por força do art. $6^{\circ}, 1$, da nova redação dada pela Resolução RDC n. 314, de 9 de dezembro de 2004.

Tal determinação é, sem sobra de dúvidas, inconstitucional já que o $\S 7^{\circ}$, do art. 150 da Constituição da República, que trata das limitações do poder de tributar estabelece que a lei poderá atribuir a sujeito passivo de obrigação tributária a condição de responsável pelo pagamento de imposto ou contribuição - não havendo qualquer previsão da possibilidade quanto à taxa - cujo fato gerador deva ocorrer posteriormente, assegurada a imediata e preferencial restituição da quantia paga, caso não se realize o fato gerador presumido.

O meio de pagamento da taxa de fiscalização sanitária federal, foi instituida pela Resolução RDC n. 23/2003 que criou a "Guia de Vigilância Sanitária - GVS Eletrônica" em seu art. 19, parágrafo único, sendo obrigatório o pagamento da taxa por meio dessa guia eletrônica por força do art. 17 e ss. da mesma Resolução. O sistema de arrecadação é on line e eletrônico. A apresentação dessa guia devidamente recolhida é condição essencial para o recebimento da documentação pela UNIAP conforme determina 0 art. 6², l, da Resolução RDC n. 314, de 9 de dezembro de 2004, que alterou as normas de análise documental, subsistindo a inconstitucionalidade e a necessidade da presença deste documento, sob 
pena de indeferimento na própria UNIAP. De acordo com o art. 13 dessa mesma Resolução, fica concedido o prazo de 60 dias para o envio da documentação após o recolhimento da taxa, sob pena de arquivamento do procedimento eletrônico.

\section{DA DEVOLUÇÃO E DO APROVEITAMENTO DAS TAXAS DE FISCALIZAÇÃO SANITÁRIA FEDERAL}

É possivel, para aqueles que fizeram o recolhimento da taxa de fiscalização sanitária federal, ter a compensação ou a devolução dos valores arrecadados, desde que haja a impossibilidade de atuação da ANVISA, comprovada através de procedimento administrativo, para utilização, pelo titular do recolhimento, como forma de quitação total ou parcial de nova solicitação de atendimento efetuada em seu nome perante a ANVISA. Essa determinação está contida no art. 41 , constante do Capítulo VII, da Resolução RDC n. 23, de 6 de fevereiro de 2003.

A impossibilidade de atuação da ANVISA para fins de pedido de restituição ou aproveitamento da taxa só poderá ser requerida nos seguintes casos: erro em virtude da natureza ou das circunstâncias materiais do fato gerador efetivamente ocorrido, desde que as medidas previstas nesta Resolução revelem-se incapazes de dar prosseguimento à petição; erro na edificação do sujeito passivo, no cálculo do montante do débito ou na elaboração ou conferência de qualquer documento relativo ao pagamento; e petição protocolada que, por fato ou ato da ANVISA, depare-se com a impossibilidade do exercício regular do poder de policia, nos termos da lei. É este o texto do art. 43 da RDC que prevê, nada mais, do que as circunstâncias aos quais o indeferimento ocorrera de plano pela UNIAP, exceto com as modificações precedidas da Resolução RDC n. 314, de 9 de dezembro de 2004.

Esse capitulo normativo também prevê a possibilidade da Administração, no caso a ANVISA, utilizar os valores depositados e, diante da solicitação de restituição ou compensação, utilizá-los primeiramente para a compensação das dividas perante esta Agência, conforme determina o $\S 2^{\circ}$, do art. 42, da Resolução RDC.

Para tanto, a compensação será precedida de notificação ao Agente Regulado para que se manifeste sobre o procedimento, no prazo de 15 dias, contado da data do recebimento, determinando a norma que o silêncio do administrado será considerado como sua aquiescência à compensação dos valores.

Analisemos, agora, o instituto da compensação como forma de extinção do crédito tributário perante o Código Tributário Nacional. A compensação é uma forma de extinção do crédito tributário previsto nos arts. 156, inciso II, e 170, ambos do Código Tributário Nacional. No art. 170 
temos a determinação de que a lei poderá, nas condições e sob as garantias que só ela estipular - não uma Resolução - ou cuja estipulação em cada caso atribuir à autoridade administrativa, autorizar a compensação de créditos tributários com créditos liquidos e certos, vencidos ou vincendos, do sujeito passivo contra a Fazenda Pública Nacional. No entanto, a taxa de fiscalização sanitária possui regras de compensação estipuladas pela Resolução RDC n. 23, de 6 de fevereiro de 2003, que, frisamos, não é uma lei, em desrespeito frontal ao que determina o principio da reserva legal. Tal compensação é ilegal face às disposições do Código Tributário Nacional. Esses requisitos foram matéria de abordagem enquanto comentário do art. 170 do Código Tributário Nacional, que Carlos Valder do Nascimento ${ }^{(24)}$ transcreveu afirmando que a autoridade administrativa pode, mas somente mediante a outorga legal, autorizar a compensação de créditos tributários com créditos liquidos e certos do sujeito passivo contra a Fazenda Pública.

Por isso, diante do principio da legalidade administrativa e tributária, a compensação no âmbito dos créditos da Fazenda Pública de origem tributário-sanitária, não é legal.

\section{CONCLUSÃO}

Identificamos, assim, que o Sistema Tributário Sanitário federal não está adequado à ordem constitucional e legal vigente possuindo, na sua grande parte, inconstitucionalidades e ilegalidades que geraram uma sobrecarga ao Setor Regulado, principalmente em relação às empresas de pequeno porte e às microempresas do setor.

Como se observa a ANVISA, independente do impedimento criado pela Constituição da República, tem editado sim regulamentos autônomos, aproximando-se da estrutura das agências norte-americanas. Porém, deve-se constar que adotamos a pior parte do sistema juridico das agências reguladoras norte-americanas e francesas, sem adotar efetivamente o sistema de controle que se exerce sobre elas ${ }^{(25)}$.

É claro que a doutrina jurídica brasileira(26), consciente dos limites legais e constitucionais dos atos das agências reguladoras brasileiras,

(24) NASCIMENTO, Carlos Valder do. Comentários ao Código Tributário nacional, p. 447.

(25) O sistema de controle norte-americano é bem complexo. Além de possuir um controle efetivo pelo Poder Judiciário, o Poder Legislativo tem importante papel no controle através da aprovação ou reprovação dos atos regulatórios num prazo máximo de 60 dias.

(26) Este entendimento de que no Brasil não existe por parte das agências reguladoras a expedição de regulamentos autônomos é unânime. No entanto, que me desculpem a doutrina do direito administrativo, a realidade é outra. A ANVISA expede regulamentos autónomos tanto quanto forem necessários para a sua atuação em conformidade com os ideais de seus agentes, sem qualquer tipo de preocupação com o princípio da legalidade e da reserva legal. Assim, a 
não admite a possibilidade da existência dos regulamentos autônomos; porém, como estamos vendo, na prática eles são maioria no setor de fiscalização sanitária.

O Sistema Tributário Sanitário não está isolado no sistema legal. Sua interpretação e aplicação deverão obedecer às regras gerais do Código Tributário Nacional e as contidas em nossa Constituição da República. Não se pode afastar a taxa de fiscalização sanitária dos principios do direito tributário como parece pretender os técnicos da ANVISA. A legalidade é um principio norteador do Estado de Direito aqui instituido e, apesar da importância que se quer dar à saúde pública e às instituições da efetividade do poder de policia administrativa atribuida à ANVISA, toda essa importância possui limites que deverão respeitar o sistema legal sob pena de contestação perante o Judiciário, como já experimentado nos sistemas estrangeiros modelos.

Não se sabe ainda porque há tantas irregularidades na instituição da Taxa de Fiscalização Sanitária federal. Somos favoráveis à uma completa remodelação da Taxa de Fiscalização Sanitária federal, através de lei, que adeque as taxas ao real contexto do Sistema Sanitário Nacional. Entendemos, ainda, a necessidade do controle pelos Poderes Legislativo e Judiciário em relação às novas edições de Resoluções da ANVISA, tendo em vista as atuações desastrosas na atividade normativa que passou por cima de principios básicos constitucionais.

Por enquanto, entendemos que a fonte da taxa de fiscalização sanitária é a lei, devendo, os operadores do direito, defender a sua vigência e contrariando a imposição das Resoluções e da Medida Provisória que alteraram a sua matéria.

\section{BIBLIOGRAFIA}

ATALIBA, Geraldo. Carga tributária e prazo de recolhimento de tributos. Revista de Direito Tributário. n. 45, p. 27-29, jul.-set.1988.

AYAD, Denise. Autoridades administrativas independentes na França Direito Regulatório, Coord. Maria Sylvia Zanella di Pietro, 2. ed., Belo Horizonte: Ed. Fórum, 2004.

BALEEIRO, Aliomar de Andrade. Direito tributário brasileiro. 9. ed., Rio de Janeiro: Forense, 1977.

BARROSO, Luis Roberto. Interpretação e aplicação da Constituição. 4. ed., São Paulo: Saraiva, 2001.

mesma preocupação transferida por Denise Ayad (Autoridades administrativas independentes na França - Direito Regulatório, 2. ed., Ed. Fórum: Belo Horizonte, 2004, p. 452), em relação a se tornar, os AAls, órgãos com superpoderes, também é nossa. Ademais, na prática isto já ocorre com bastante freqüência. 
BASTOS, Celso Ribeiro. Curso de direito financeiro e de direito tributário. 3. ed., São Paulo: Saraiva, 1995.

CARRAZZA, Roque Antônio. Curso de direito constitucional tributário. 16. ed., São Paulo: Malheiros Ed., 2001.

CARVALHO, Cristiano et ali. Direito sanitário brasileiro. São Paulo: Quartier Latin, 2004.

COELHO, Sacha Calmon Navarro. Comentários à Constituição de 1988. 5. ed., Rio de Janeiro: Forense, 1993.

COLLET, Martin. Le contrôle juridictionnel des actes des autorités administratives indépendantes. Bibliothèque de droit public n. 233, Paris: LGDJ, 2003.

COLLIARD Claude-albert, TIMSIT, Gerard. Les autorités administratives indépendantes. Paris: Press Universitaires de France, 1988.

COSTA, Nelson Nery. Processo administrativo e suas espécies. 4. ed., Rio de Janeiro: Forense, 2003.

DALLARI, Sueli Gandolfi; BARBER-MADDEN, Rosemary; TORRES-FERNANDES, Marilia de Castro et al. Advocacia em saúde no Brasil contemporâneo. Revista de Saúde Pública, v. 30, n. 6, p. 592-601, dez. 1996.

DALLARI, Sueli Gandolfi. Uma nova disciplina: o direito sanitário. Revista de Saúde Pública, vol. 22, n. 4, p. 327-334, agosto de 1988.

DI PIETRO, Maria Sylvia Zanella. Direito administrativo. 10. ed., São Paulo: Atlas, 1999.

DI PIETRO, Maria Sylvia Zanella et alii. Direito regulatório. 2. ed., Belo Horizonte: Fórum, 2004.

FAGUNDES, Miguel Seabra. O controle dos atos administrativos pelo Poder Judiciário. 3. ed., Rio de Janeiro: Revista Forense, 1957.

GELLHORN, Ernest; LEVIN, Ronald M. Administrative law and process. Minesotta: West, 1997.

LUNARDELLI, Pedro Guilherme Accorsi. Isenções tributárias. São Paulo: Dialética, 1999.

MARTINS, Ives Gandra da Silva et alii. Comentários ao Código Tributário Nacional. Rio de Janeiro, 1997.

MELLO, Celso Antônio Bandeira de. Curso de direito administrativo. 17. ed., São Paulo: Malheiros Ed., 2004.

MELLO, Vanessa Vieira de. Regime juridico da competência regulamentar. São Paulo: Dialética, 2001.

NOGUEIRA, Ruy Barbosa. Curso de direito tributário. 14. ed., São Paulo: Saraiva, 1995.

SABBAG, Eduardo de Moraes. Elementos do direito - direito tributário. 5. ed., São Paulo: Prima Cursos Preparatórios, 2004. 